\title{
CIRCUNSTANCIADORES TEMPORAIS: O LIVRO DIDÁTICO COMO FERRAMENTA DE AMPLIAÇÃO DO REPERTÓRIO LINGUÍSTICO DOS ESTUDANTES DO SÉTIMO ANO DO ENSINO FUNDAMENTAL
}

\section{ARTIGO DE REVISÃO}

ROCHA, Ariana Góes ${ }^{1}$, LEAL, Liviane Rodrigues dos Santos ${ }^{2}$

ROCHA, Ariana Góes. LEAL, Liviane Rodrigues dos Santos. Circunstanciadores temporais: o livro didático como ferramenta de ampliação do repertório linguístico dos estudantes do sétimo ano do ensino fundamental. Revista Científica Multidisciplinar Núcleo do Conhecimento. Ano. 06, Ed. 08, Vol. 02, pp. 143-152. Agosto 2021. ISSN: 2448-0959, Link de acesso: https://www.nucleodoconhecimento.com.br/educacao/ferramenta-de-ampliacao, DOI: 10.32749/nucleodoconhecimento.com.br/educacao/ferramenta-de-ampliacao

\section{RESUMO}

Este artigo aborda sobre o uso dos circunstanciadores temporais no Livro didático "Se Liga na Língua - Leitura, Produção de Texto e Linguagem - $7^{\circ}$ ano", da Editora Moderna (2018). Dito isso, Circunstanciadores temporais são conectores que expressam relações de tempo e fazem a juntura entre as partes do texto, promovendo a sequenciação das informações. Trata-se de uma pesquisa bibliográfica que tem como ponto de partida a realidade de alguns alunos que não são exitosos em tarefas linguísticas por conta da limitação das habilidades e competências exploradas no contexto escolar. Tem-se como objetivo discutir os

\footnotetext{
${ }^{1}$ Mestra em Letras pela Universidade Federal de Sergipe (2018). Especialista em Estudos Linguísticos e Literários pela Faculdade Santíssimo Sacramento (2010). Graduada em Letras Vernáculas pela Universidade do Estado da Bahia (2008).

${ }^{2}$ Especialista em Estudos Linguísticos e Literários pela Faculdade Santíssimo Sacramento (2010) e em Docência do Ensino Superior pela Universidade Cândido Mendes (2015). Graduada em Letras Vernáculas pela Universidade do Estado da Bahia (2008).
}

RC: 93584

Disponível em: https://www.nucleodoconhecimento.com.br/educacao/ferramenta-de- 
elementos coesivos em questão e suas possibilidades em sala de aula, com enfoque no livro didático, que é uma ferramenta basilar de ensino. Diante do estudo realizado, concluiu-se que os docentes precisam implementar estratégias que aprimorem a execução das atividades, propostas pelo compêndio escolar, ampliando, assim, o repertório linguístico dos estudantes.

Palavras-chave: Circunstanciadores temporais, Livro didático, Repertório linguístico.

\section{INTRODUÇÃO}

No Brasil, avaliações diagnósticas oficiais sinalizam como estão os índices de aprendizagem em escala nacional. Os alunos são submetidos a exames oficiais do governo e os resultados são analisados de maneira macro (por região) e micro (por unidade escolar).

Diagnósticos como Prova Brasil (2018) e o Programa Internacional de Avaliação de Estudantes (PISA, 2018) avaliam os níveis de proficiência de leitura e da escrita dos discentes. Portanto, fazer com que os alunos alcancem bons resultados nessas atividades tornou-se um dos objetivos dos professores de língua portuguesa. Nesse sentido, uma das metas é capacitar o estudante para obter êxito nessas provas, não apenas para garantir um bom renome à instituição escolar, mas para garantir, de fato, a aprendizagem em língua materna no que tange à leitura e escrita.

É motivo de inquietação perceber que alguns alunos, todavia, não conseguem ter sucesso em tarefas linguísticas por conta da limitação das habilidades e competências que deveriam estar sendo exploradas no próprio contexto escolar. Tal realidade requer do docente o comprometimento em buscar estratégias que aprimorem e substanciem as habilidades que carecem de ampliação.

A proficiência na escrita é um dos desafios postos para os alunos na sociedade letrada. Para saber escrever com as adequações necessárias em cada tipo de texto, é necessário ter um repertório linguístico amplo e diversificado para que haja a seleção dos itens

RC: 93584

Disponível em: https://www.nucleodoconhecimento.com.br/educacao/ferramenta-de- 
que melhor se ajustam ao propósito comunicativo (FREITAG; ROCHA, 2018, p. 10).

Em cada ciclo do ensino fundamental competências e habilidades distintas são desenvolvidas no campo da linguagem. Em relação à escrita, no sétimo ano do ensino fundamental, espera-se, de acordo com os PCNs (BRASIL, 1998, p. 97), que os alunos possam redigir diferentes tipos de textos de forma coerente e coesa, realizando escolhas de elementos lexicais e sintáticos, ajustando-os às circunstâncias de formalidade e propósito de interação determinado.

Nesse contexto, os gêneros discursivos não podem ser esquecidos. Segundo Bakhtin (2003, p. 261), todos os diversos campos da atividade humana estão ligados ao uso da linguagem, do que se pode compreender que as formas de uso são multiformes. O autor ainda defende que os gêneros discursivos possuem três características importantes: o conteúdo temático, o estilo e a construção composicional, elementos determinados pela especificidade de um determinado campo da comunicação.

Para Bakhtin (2003, p. 262), a riqueza e a diversidade de gêneros são infinitas porque são inesgotáveis as possibilidades da multiforme atividade humana. A importância de se destacar a pluralidade e infinidade dos gêneros discursivos é a clareza que o docente precisa ter ao escolher o gênero propício para cada objetivo de ensino da língua, que é dinâmica, heterogênea e, como Bakhtin aponta, infinita em construções de usos.

Retornando a análise para o sétimo ano do ensino fundamental, que tipo de gêneros são eficazes ou mais apropriados para trabalhar uma sequência textual, seja ela narrativa, descritiva, explicativa, argumentativa, injuntiva etc.? É papel do docente levar os alunos a ter uma maior familiaridade com os elementos linguísticos composicionais de cada gênero. Envolver-se com tais aspectos melhora o desempenho de suas funções comunicativas. Nota-se que, dessa forma, é necessário ampliar o repertório linguístico dos alunos para que eles tenham

$\mathrm{RC}: 93584$

Disponível em: https://www.nucleodoconhecimento.com.br/educacao/ferramenta-de- 
autonomia para escolherem aqueles que têm maior pertinência nos textos que escrevem. Trata-se da adequação de uso.

As narrativas possuem uma característica marcante: a temporalidade. A marcação do tempo pode ser estabelecida com elementos formais ou informais, a depender do tipo de texto que o aluno estiver em contato. Os circunstanciadores temporais, termo cunhado por Martelotta (1993), além de expressarem as relações temporais, funcionam também como conectores, pois fazem a juntura temporal entre as partes do texto e promovem a sequenciação das informações, o que configura a função de elementos coesivos.

Como o livro didático "Se Liga na Língua - Leitura, Produção de Texto e Linguagem", da Editora Moderna (2018) apresenta os circunstanciadores temporais para os alunos e qual a relevância de analisar o material didático? O livro didático é o recurso mais utilizado pelos professores nas aulas de Língua Portuguesa. Devido ao caráter subsidiário e pedagógico que ele desempenha, o docente deve analisá-lo mais criticamente para perceber os pontos positivos e negativos que o material apresenta e assim implementar estratégias que aprimorem a execução das atividades.

Ao examinar com mais cuidado o livro didático, o professor pode complementar informações e adequar os exercícios à realidade social e cultural da comunidade em que o material é utilizado. Por isso, ele não pode ser utilizado de qualquer maneira, pois é a ferramenta mais acessível ao aluno na construção do seu conhecimento (FREITAG; ROCHA, 2018).

Em concordância com Silva e Santos (2015), não se pode afirmar que o livro didático de português continua reproduzindo as mesmas práticas e teorias de décadas passadas. Entretanto, elas ressaltam que

Já encontramos nos livros didáticos abordagens sobre a variação linguística, gêneros textuais, linguagem multimodal, temas frequentes nos estudos e pesquisas linguísticas das últimas décadas. No entanto, por trás dessas abordagens muitas vezes ainda

$\mathrm{RC}: 93584$

Disponível em: https://www.nucleodoconhecimento.com.br/educacao/ferramenta-de- 
predominam concepções de língua, linguagem e gramática cujo foco são apenas regras e juízos de valor sobre "certo" e "errado" (SILVA; SANTOS, 2015, p. 33).

Nessa linha, seguem as propostas apresentadas pelos autores Wilton Ormundo e Cristiane Siniscalchi (2018), em relação aos circunstanciadores temporais, que são os advérbios de tempo semanticamente marcados, classificados em:

a. Circunstanciador de tempo determinado: definem o tempo em que o fato ocorre (agora, às sete horas etc.);

b. Circunstanciador de tempo indeterminado: não dão indicações precisas do momento da ocorrência dos eventos específicos sequenciais (nunca, geralmente, antigamente, de vez em quando etc.);

c. Circunstanciador de tempo iterativo: indica a frequência com que o evento se refere ao longo do tempo (às vezes, duas vezes por semana, uma vez por mês etc.);

d. Circunstanciador de tempo simultâneo: expressa a ideia de que o evento ao qual se liga ocorre simultaneamente ao outro, ou seja, os eventos ocorrem ao mesmo tempo (ao mesmo tempo, enquanto isso etc.).

Percebendo as particularidades semânticas que os circunstanciadores temporais apresentam, optou-se por trabalhar este conceito ao invés dos advérbios e locuções adverbiais de tempo. Considerando que o conceito de circunstanciadores temporais advém dos advérbios de tempo e das locuções adverbiais temporais, cabe, então, uma análise da forma como este conteúdo é abordado no livro didático escolhido.

\section{LIVRO DIDÁTICO: CIRCUNSTANCIADORES EM FOCO}

O livro didático "Se Liga na Língua - Leitura, Produção de Texto e Linguagem", da Editora Moderna (2018), traz, segundo os autores Wilton Ormundo e Cristiane Siniscalchi (2018), uma proposta integralmente alinhada às concepções da BNCC

RC: 93584

Disponível em: https://www.nucleodoconhecimento.com.br/educacao/ferramenta-de- 
(2017), que preconiza o desenvolvimento pleno do aluno como ser integrante e protagonista de práticas sociais nas diversas áreas de atuação. Assim, o estudante é provocado a construir competências que mobilizem habilidades, atitudes e valores que o ajude a resolver demandas da vida cotidiana, do exercício da cidadania e do mundo do trabalho.

A obra - composta por seções que contemplam a leitura, produção de texto, oralidade, análise linguística, artes, gêneros digitais, interdisciplinaridade e material digital - propõe atividades de naturezas que permitam aos estudantes, com potenciais diferentes, alcançar notoriedade, trabalhando conjuntamente para a conquista de um objetivo, construindo e realizando projetos que ampliem sua autoestima, capacidade de diálogo, resiliência e responsabilidade.

Gêneros textuais diversos, inclusive os que circulam no universo digital (blogs, tirinhas, infográficos), bem como vários tipos de obras de arte (cinema, teatro, documentário, videoclipe) estão presentes nesse trabalho, que pretende, entre outras coisas, relacionar o complexo universo da Língua Portuguesa ao conhecimento prévio dos alunos, resgatando o que já sabem a respeito de um assunto, ampliando seu repertório linguístico, explorando sua criatividade, expressando-se criticamente, utilizando uma língua viva.

Os autores, Ormundo e Siniscalchi (2018), introduzem o conteúdo advérbios por meio de uma tirinha com o objetivo de levar o aluno a perceber o valor semântico das palavras dessa classe gramatical e a maneira como podem acrescentar informações às ideias expressas por verbos, adjetivos, advérbios e orações inteiras (EF07LP09). Destacam o mecanismo de modalização, um dos responsáveis por indicar a intenção ideológica sobre o conteúdo expresso ou implícito em diversos textos, conforme as habilidades EF07LP14/ EF89LP31, descritas na BNCC (2017).

A Tira apresenta, geralmente, uma temática humorística, satírica, de cunho social ou político, com linguagem de fácil entendimento, empregando recursos como:

RC: 93584

Disponível em: https://www.nucleodoconhecimento.com.br/educacao/ferramenta-de- 
imagens, balões, diálogos. A leitura desse gênero é considerada uma atividade social, um processo de compreensão ativa, no qual os sentidos são construídos a partir da relação dialógica estabelecida entre autor-texto-interlocutor.

Os próximos textos, presentes no livro didático, fazem um convite aos alunos para observarem o sentido das palavras e substituí-las sem prejudicar o propósito da oração, considerando as circunstâncias nas quais estão inseridas.

É válido ressaltar que o advérbio não foi apresentado ao aluno, imediatamente, como um conceito. O acesso ao conteúdo parte sempre da análise de um texto, com enunciados que evocam a percepção desses elementos no texto. Só depois de exploradas as palavras no sentido dos textos é que uma breve definição é feita: "A classe de palavras que adiciona circunstâncias - de tempo, lugar, de modo etc. aos processos verbais é chamada de advérbio." (ORMUNDO e SINISCALCHI, 2018)

Em seguida, é apresentado a tabela de modelo canônico para que os alunos identifiquem e classifiquem os advérbios, destacando alguns exemplos de uso na construção de orações.

Contudo, é importante destacar que não há, no exemplar analisado, atividades que explorem as distinções semânticas entre os circunstanciadores temporais. É apresentado, somente, uma lista genérica sem levar o aluno a perceber que antes e agora, por exemplo, são advérbios de tempo com marcação temporal diferenciada. Também não foi encontrado no exercício de produção de texto elementos que trabalhassem a função dos circunstanciadores na construção textual, como conectivos que promovem a coesão.

De acordo com Koch (2013) a coesão textual acontece quando existem relações de sentido no interior do texto e é realizada através do sistema léxico-gramatical. Por isso,

$\mathrm{RC}: 93584$

Disponível em: https://www.nucleodoconhecimento.com.br/educacao/ferramenta-de- 
A coesão, por estabelecer relações de sentido, diz respeito ao conjunto de recursos semânticos por meio dos quais uma sentença se liga com a que veio antes, aos recursos semânticos mobilizados com o propósito de criar textos. A cada ocorrência de um recurso coesivo no texto, denominam "laço", "elo coesivo" (KOCH, 2013, p. 16)

Dessa maneira, os circunstanciadores temporais, se explorados na construção do texto, podem marcar linguisticamente a sequência temporal em que os eventos descritos acontecem. Logo, são esses elementos que fazem com que o texto seja fluído e compreensível, além de diversificados em relação aos itens temporais escolhidos.

A coesão sequencial, ou sequenciação, diz respeito aos procedimentos linguísticos por meio dos quais se estabelecem, entre segmentos do texto, diversos tipos de relações semânticas e/ou pragmáticas, à medida que faz o texto progredir $(\mathrm{KOCH}$, 2013). No nível intersequencial, estão os marcadores de situação ou ordenação tempo-espaço. Nesse aspecto, é que se pode incluir os circunstanciadores temporais como elementos coesivos.

\section{CONSIDERAÇÕES FINAIS}

É sabido que existe uma forte ligação entre linguagem, escrita e poder, uma vez que a maioria da população não tem acesso a uma escolarização eficaz. Em vista disso, se tem como questionamento: Se estas pessoas não têm o acesso a um ensino "de qualidade", como elas poderão ter vez e voz em uma sociedade que gira em torno do letramento?

O livro didático, utilizado pelos professores cotidianamente, deve trazer questões que priorizem uma reflexão linguística eficaz, seja focando no gênero abordado e sua função ou nos mecanismos linguísticos que revelem a finalidade do texto. Ademais, o protagonismo da gramática normativa, com suas regras e nomenclaturas, têm de ser revisto, equilibrado, a fim de que a interpretação e a

$\mathrm{RC}: 93584$

Disponível em: https://www.nucleodoconhecimento.com.br/educacao/ferramenta-de- 
produção textual - ferramentas basilares na aquisição do repertório linguístico e consequente autonomia dos estudantes em relação à escrita - sejam trabalhadas de forma mais produtiva e inclusiva.

É importante que os docentes trabalhem as diferenças linguísticas e culturais dos educandos, propondo atividades que integrem a linguagem social dos mesmos, a fim de tornar o ambiente escolar propício para que todo indivíduo possa se expressar da forma como sabe, e, aos poucos, possa apropriar-se de outras linguagens sociais.

A tarefa didática deve ser organizar de tal maneira que os alunos transitem das linguagens utilizadas nas situações mais informais e coloquiais que já dominam, ao entrarem na escola, a outras mais formais, a fim de conhecer seus modos de funcionamento e aprender a utilizá-las.

Um modelo de trabalho exitoso ocorreu na cidade de Estância/ Sergipe, com alunos do sétimo ano do ensino fundamental. $\mathrm{Na}$ atividade diagnóstica realizada pela professora (ROCHA, 2018), percebeu-se que os discentes usavam em suas narrativas escritas, itens como "aí", "e", "daí" e "então" para marcar a sequência temporal dos eventos. Depois de terem acesso a um módulo didático, criado exclusivamente para eles, para amplificar o repertório linguístico dos marcadores temporais, notou-se um avanço significativo nos textos, não apenas quantitativamente, mas qualitativamente, pois os alunos usaram os circunstanciadores temporais de modo adequado em cada atividade proposta.

A necessidade de criação de uma ferramenta pedagógica, como o módulo, levanta uma reflexão: o livro não esgota totalmente o conteúdo trabalhado. Por isso, os professores podem desenvolver ou pesquisar na internet trabalhos que complementem o livro didático.

RC: 93584

Disponível em: https://www.nucleodoconhecimento.com.br/educacao/ferramenta-de- 
Portanto, torna-se crucial uma prática docente que trabalhe a Língua Portuguesa como uma das formas de expressão, viva, plural e dinâmica, pois é nessa concepção, que ela cumpre a função de expressão do pensamento, comunicação e interlocução. Decodificar, interpretar, relacionar, ler, em seu sentido mais amplo, são etapas/processos que se interligam. Os alunos, ao concluírem a Educação Básica, devem ser capazes de utilizar a leitura e a escrita nas diferentes situações do cotidiano que configuram o letramento da vida social. Tais habilidades são essenciais para o exercício da cidadania, na esfera individual, coletiva, social e política.

\section{REFERÊNCIAS}

BRASIL, Base Nacional Comum Curricular. Brasília: MEC, 2017. Disponível em:<https://basenacionalcomum.mec.gov.br/>. Acesso em 7 maio 2018.

Brasil no PISA. Relatório Nacional. Brasília, DF: INEP/MEC, 2018.

Resultados - SAEB/Prova Brasil. Disponível em: < http://portal.inep.gov.br/web/guest/educacao-basica/saeb/resultados >. Acesso em 10 set. 2018.

Secretaria de Educação Fundamental. Parâmetros Curriculares Nacionais: língua portuguesa. Secretaria de Educação Fundamental. Brasília, 1998.

BAKHTIN, M.M. O discurso no romance. In: M.M. BAKHTIN (1975). Questões de literatura e de estética: a teoria do romance. São Paulo: UNESP/HUCITEC, 1934. . O problema dos gêneros discursivos. In: Estética da criação verbal Tradução Paulo Bezerra. São Paulo: Martins Fontes. 2003

RC: 93584

Disponível em: https://www.nucleodoconhecimento.com.br/educacao/ferramenta-de- 
FREITAG, Raquel Meister Ko. Freitag; DAMACENO, Taysa Mércia dos Santos Souza. Livro didático, Gramática, leitura e ensino de língua portuguesa. Contribuições para a prática docente. São Cristóvão: Editora UFS, 2015.

KOCH, Ingedore G. Villaça, A coesão textual. 22.ed.São Paulo: Contexto 2013.

MARTELOTTA, Mário Eduardo T. Os circunstanciadores temporais e sua ordenação: uma visão funcional. Disponível em: $>$ http://www.discursoegramatica.letras.ufrj.br/download/tese_doutorado_martelotta.p df> Acesso em 23 mar. 2017.

ORMUNDO, Wilton; SINISCALCHI, Cristiane. Se liga na língua: leitura, produção de texto e linguagem. São Paulo: Moderna, 2018, 1 ed, $7^{0}$ ano.

ROCHA, Ariana Góes. Circunstanciadores temporais em narrativas escritas. 2018. 138 f. Dissertação (Mestrado Profissional em Letras) - Universidade Federal de Sergipe, São Cristóvão, SE, 2018.

SILVA, Maria Denise Oliveira da; SANTOS, Tânia Andrade Oliveira. Pronomes pessoais no livro didático. IN: FREITAG, Raquel Meister Ko. Freitag; DAMACENO, Taysa Mércia dos Santos Souza. Livro didático. Gramática, leitura e ensino de língua portuguesa. Contribuições para a prática docente. São Cristóvão: Editora UFS, 2015.

Enviado: Abril, 2021.

Aprovado: Agosto, 2021.

RC: 93584

Disponível em: https://www.nucleodoconhecimento.com.br/educacao/ferramenta-de- 